\title{
Pulsed Polarization of Lambda Probes - Evaluation of the Polarization Current
}

\author{
Sabine Fischer ${ }^{1,2}$, Roland Pohle $^{2}$, Erhard Magori ${ }^{2}$, Boris Farber ${ }^{3}$, Maximilian Fleischer ${ }^{2}$, Ralf Moos ${ }^{1}$ \\ ${ }^{1}$ University of Bayreuth, Functional Materials, 95440 Bayreuth, Germany \\ 2 Siemens AG, Corporate Technology, 81739 Munich, Germany \\ sabine.fischer@uni-bayreuth.de \\ ${ }^{3}$ BJR Sensors, LLC, OH 44139 Solon, USA
}

\begin{abstract}
Conventional thimble type lambda sensors show strong response on $\mathrm{NO}_{\mathrm{x}}$ by evaluation of the open circuit discharge characteristics after defined polarizations with alternating signs. The sensor signal is dependent on oxygen or water concentration but the influence on discharge characteristics is consistent with Nernstian behavior. This confirms the feasibility of a pulsed mode operated lambda probe as a $\mathrm{NO}_{x}$ sensor for exhaust gas measurements. To find the underlying mechanism of this polarization technique, the current during the voltage pulse is evaluated in a simulated combustion exhaust gas with varying oxygen and moisture levels. By increasing the oxygen or water content in the exhaust the polarization current decreases at both polarization directions. Platinum oxidation during voltage pulses is assumed to be responsible for this effect.
\end{abstract}

Key words: NO detection, lambda probe, discharge characteristic, polarization current, platinum oxide

\section{Introduction}

In order to monitor the function of the exhaust gas aftertreatment system, two lambda sensors are installed upstream and downstream of the three-way catalyst [1,2]. In lean $\mathrm{NO}_{x}$ storage catalysts, $\mathrm{NO}_{\mathrm{x}}$ sensors have been added to wide-band and binary lambda sensor. However, it is unclear whether the sensors are accurate enough for future on board diagnostics [3,4]. Also, they are more costly than conventional lambda sensors. In the past years, several approaches were undertaken to detect $\mathrm{NO}_{x}$ in the exhaust. To date, only few types of automotive exhaust gas $\mathrm{NO}_{\mathrm{x}}$ sensors are on the market, maybe due to their high cost that originates from the complex setup in ceramic multilayer technology [2,3]. Due to its low costs, the classic lambda sensor as a potentiometric solid electrolyte concentration cell ("Nernst cells") is the preferred exhaust gas sensor [5].

Our approach is to use standard thimble-type lambda probes, which are known as robust, reliable, and cost-effective sensors in the exhaust, as $\mathrm{NO}_{\mathrm{x}}$ sensors. For this purpose, a dynamic measurement technique is used: pulsed voltages are applied to such zirconiabased oxygen sensors and the self-discharge behavior in between the voltage pulses is investigated. We already have shown that the open circuit discharge characteristics of conventional thimble type lambda sensors, which are evaluated after defined polarizations with alternating signs, depend strongly on $\mathrm{NO}_{x}$, independently if $\mathrm{NO}$ or $\mathrm{NO}_{2}$ is dosed $[6,7,8]$.

To investigate the sensor mechanism, the focus of this study is on polarization currents during alternating voltage pulses; furthermore the influence of different oxygen and water concentrations is evaluated.

\section{Experimental}

After polarization with voltage pulses of opposite signs but equal amplitudes, the open circuit discharge curves of the thimble type lambda probe are measured. Fig. 1 illustrates the pulse method and the signs of polarization pulses as related to the design of the lambda sensor; during so called positive polarization voltage, the outer electrode of the sensor is on a higher potential so that the negatively charged oxygen ions move to the outer electrode.

The optimum parameters of the polarization technique are a polarization amplitude of $U_{0}=2.5 \mathrm{~V}$ with a pulse duration of $t_{0}=1 \mathrm{~s}$. Subsequently the self discharge voltage of the sensor is recorded for a duration of $t_{1}=10 \mathrm{~s}$ $[6,7,8]$. 


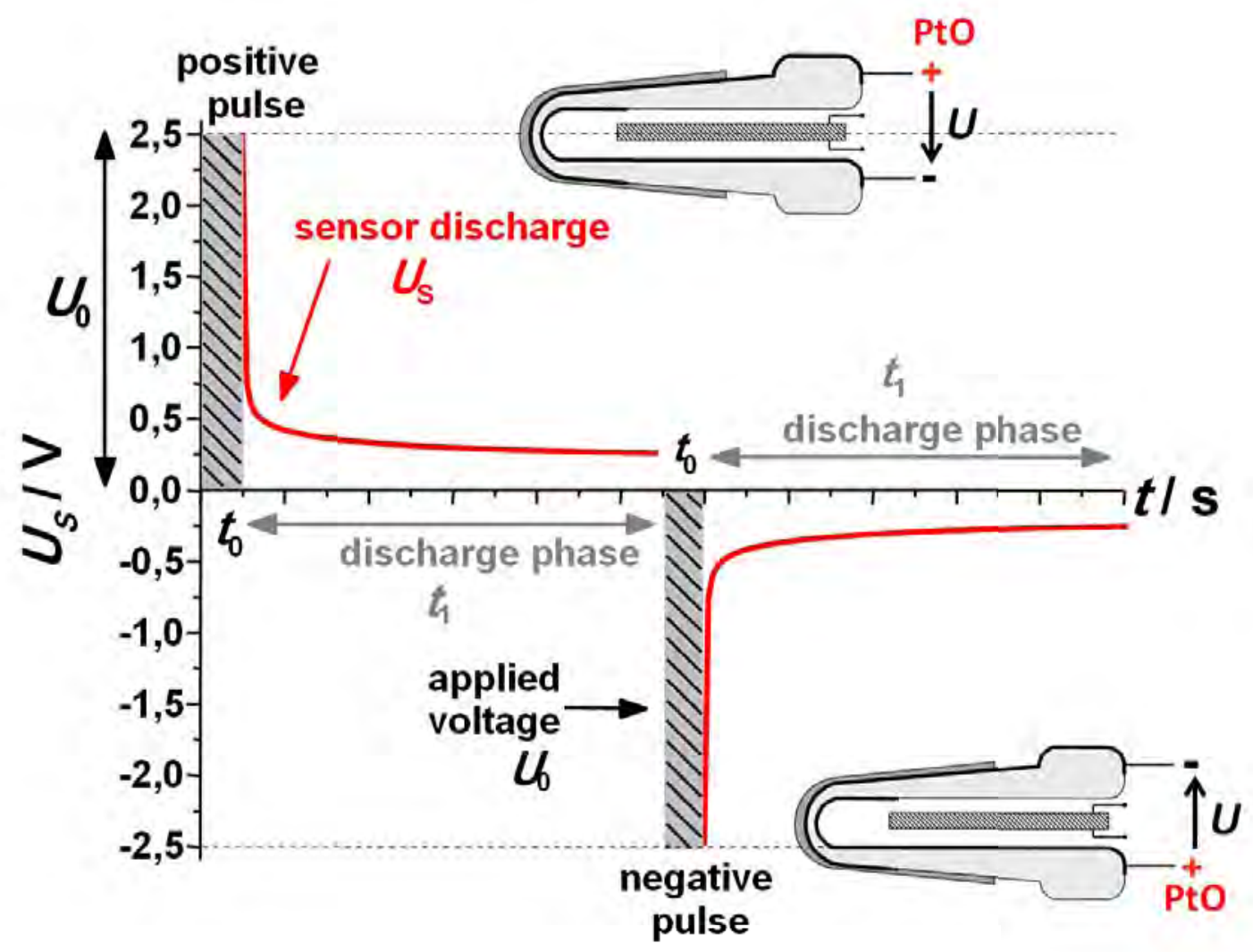

Fig. 1. Sketch of the pulsed polarization method. Indicated is the sensor principle, the polarities during polarization, and the formation of platinum oxide (see text)

In addition to discharge characteristics, the polarization current during alternating voltage pulses is measured in a simulated combustion exhaust with variable oxygen and water contents at a constant $\mathrm{CO}_{2}$ level of $5 \%$. At oxygen variation from 0 to $20 \%$, the water concentration is hold constant at $10 \%$. Furthermore, the water concentration is changed in the range from 0 to $10 \%$ at a constant oxygen content of $10 \%$. All measurements are carried out at a gas temperature of $200{ }^{\circ} \mathrm{C}$ and a voltage of the internal heater of the lambda probe of $12 \mathrm{~V}$.

\section{Results and discussion}

At both polarization signs (cf. figs. 2,4 and figs. 3,5$)$, the current $I_{\text {polarization }}$ decreases with time. The voltage $U_{0}$ is applied for a short time. The charging current at the beginning of the polarization is only limited by the internal resistance of the lambda probe. Additionally, caused by the high polarization voltage, the oxygen ions accumulate at the positively charged electrode and form platinum oxide according to [9]:

$$
\mathrm{Pt}+\mathrm{xO}^{2-} \rightarrow \mathrm{PtO}_{\mathrm{x}}+2 \cdot \mathrm{xe}^{-} \text {. }
$$

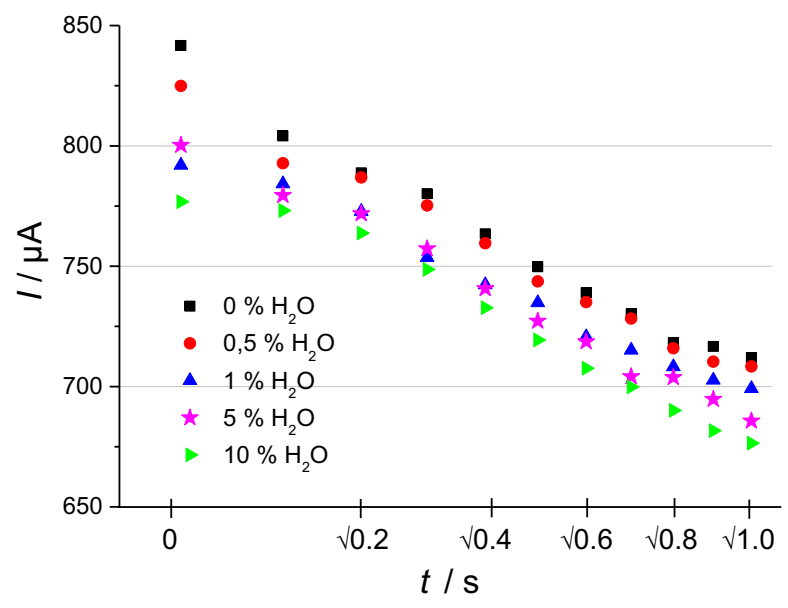

Fig. 2. Influence of water content on the polarization current during positive voltage pulse

As a consequence thereof, the resistance of the electrode increases over time and the current decreases according to Ohm's law $(U=R \cdot l)$. Please note that in figs. 2 - 5 the square root of the time is plotted as an abscissa. The square root of time dependency of the polarization current confirms the platinum oxidation formation by polarization, since such a time-dependent behavior is typical for platinum oxide growth [9]. 
This dependency is especially visible during positive polarization.

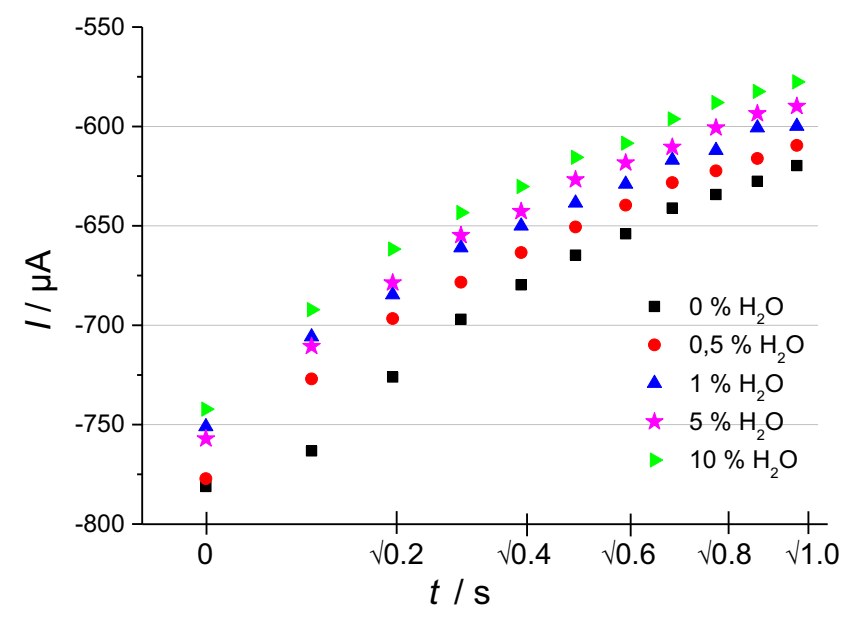

Fig. 3. Influence of water content on the polarization current during negative voltage pulse

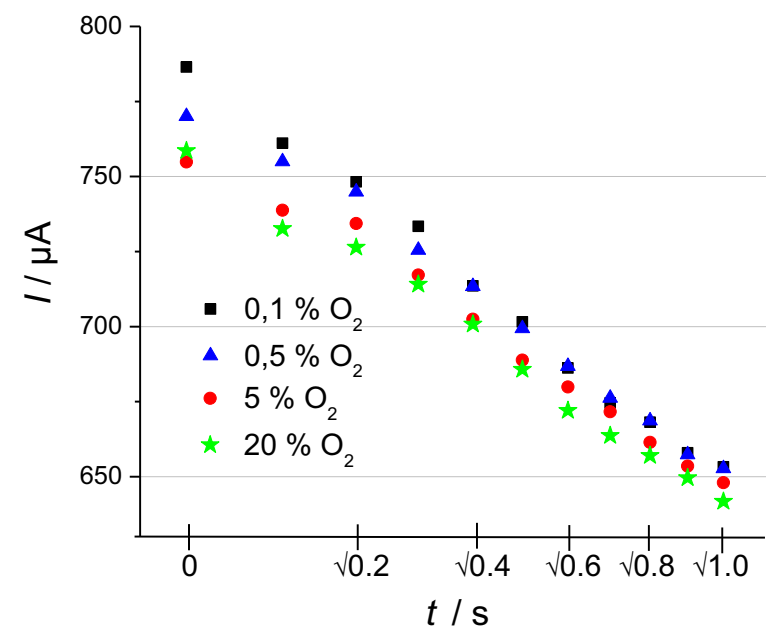

Fig. 4. Influence of oxygen content on the polarization current during positive voltage pulse

By comparing alternating polarization signs, the current at the beginning of the voltage pulses is nearly on the same level, whereas the respective current change later in the voltage pulses differs according to the polarity of the polarization. A consequence for that is a higher current level at the end of the positive polarization, which corresponds to more charge transport during the overall voltage pulse. During positive voltage pulses the transferred charge is approximately $60-70 \mu \mathrm{C}$ higher compared to the negative polarization. This effect is independent of the composition of the gas atmosphere. The evaluation of this charge difference is based on an integration of the current over polarization time. Consequently, a higher amount of platinum oxide is always formed at the outer electrode. The larger platinum surface of this electrode could be an explanation for this effect, because more platinum sites are available for oxidation.

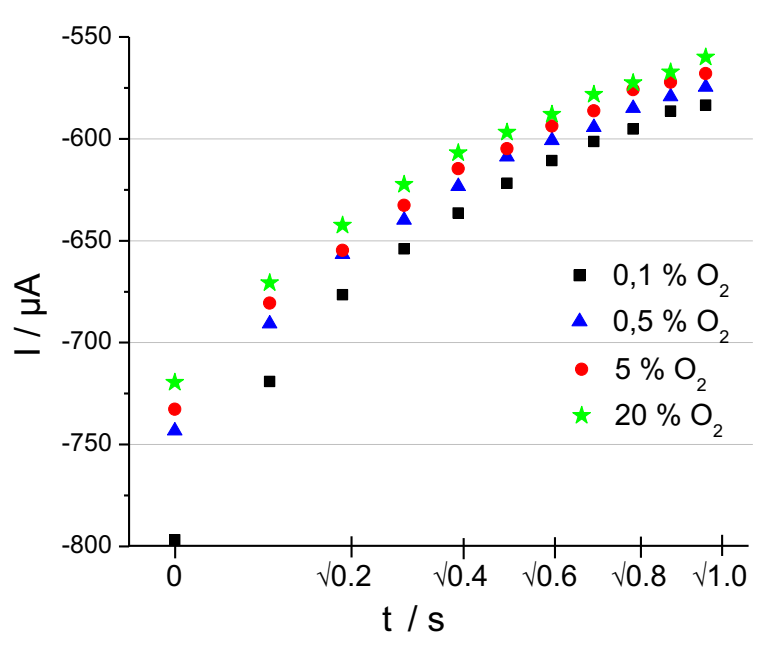

Fig. 5. Influence of oxygen content on the polarization current during negative voltage pulse

\section{Conclusion, summary and outlook}

In order to find the underlying mechanism of the polarization technique for NO detection by pulsed polarization, the current during the voltage pulse is evaluated in simulated combustion exhaust gas with varying oxygen and moisture levels.

By increasing the oxygen or water content in the exhaust the polarization current decreases at both polarization signs. Platinum oxidation during voltage pulses is assumed to be responsible for that effect and play therefore an essential role for the sensor mechanism.

In order to get a deeper insight in the fundamentals of the sensor mechanism and to understand which reactions take place during the voltage pulses and self discharge periods, a simplified sensor system is under investigation. Measurements at simple Pt electrodes on YSZ are undertaken to the end that the effects of reference atmosphere and sensor structure are excluded. Reactions taking place at Pt I YSZ system should also occur at the thimble-type lambda probes during pulsed potential method and are assumed to be responsible for sensor effect. 


\section{References}

[1] E. Ivers-Tiffée, K.H. Härdtl, W. Menesklou, J. Riegel, Principles of solid state oxygen sensors for lean combustion gas control, Electrochimica Acta 47, 807-814 (2001); doi: 10.1016/S0013-4686(01)00761-7

[2] R. Moos, A Brief Overview on Automotive Exhaust Gas Sensors Based on Electroceramics, International Journal of Applied Ceramic Technology, 2, 401-413 (2005); doi: 10.1111/j.1744-7402.2005.02041.x

[3] U.G. Alkemade, B. Schumann, Engines and exhaust after treatment systems for future automotive applications, Solid State lonics, 177, 2291-2296 (2006); doi: 10.1016/j.ssi.2006.05.051

[4] Y.W Kim and M. Van Nieuwstadt, Threshold Monitoring of Urea SCR Systems, SAE paper 2006-01-3548 (2006); doi:10.4271/2006-01-3548

[5] J. Riegel, H. Neumann, H.M. Wiedenmann, Exhaust gas sensors for automotive emission control, Solid State Ionics 152-153, 783-800 (2002); doi: 10.1016/S0167-2738(02)00329-6

[6] S. Fischer, R. Pohle, B. Farber, R. Proch, J. Kaniuk, M. Fleischer, R. Moos, Method for detection of NOx in exhaust gases by pulsed discharge measurements using standard zirconiabased lambda sendors, Sensors and Actuators $B$ : Chemical, 147, 780-785 (2010); doi: 10.1016/j.snb.2010.03.092

[7] S. Fischer, R. Pohle, U. Guth, B. Farber, M. Fleischer, R. Moos, Pulsed-potential method for NOx detection using standard zirconia-based lambda sensors, Proceedings of the 15th International Conference on Sensors and Measurement Science, 7.-9. June 2011, Nürnberg, 538-542 (2011); doi: $10.5162 /$ sensor $11 / \mathrm{d} 3.4$

[8] S. Fischer, R. Pohle, E. Magori, D. SchönauerKamin, M. Fleischer, R. Moos, Pulsed Polarization of Platinum Electrodes on YSZ, Solid State Ionics, 225, (2012) 371-375, doi: 0.1016/j.ssi.2012.03.020

[9] A. Jaccoud, C. Falgairette, G. Fòti,

C. Comninellis, Charge storage in the $\mathrm{O}_{2(\mathrm{~g})}, \mathrm{Pt} / \mathrm{YSZ}$ system, Electrochimica Acta, 52, 7927-7935 (2007); doi: 10.1016/j.electacta.2007.06.046 